\title{
Gelatin Coated Capsule Dosage Form
}

National Cancer Institute

\section{Source}

National Cancer Institute. Gelatin Coated Capsule Dosage Form. NCI Thesaurus. Code C42936.

A capsule covered with a thin layer of gelatin. 